\title{
Configuración de una voz poética piedra a piedra
}

Paisajes geológicos en Andrés Sánchez Robayna

\section{Claire Laguian}

\section{(2) OpenEdition \\ Journals}

Edición electrónica

URL: http://journals.openedition.org/agedor/1513

DOI: 10.4000/agedor.1513

ISSN: 2104-3353

Editor

Laboratoire LISAA

Referencia electrónica

Claire Laguian, «Configuración de una voz poética piedra a piedra », L'Âge d'or [En línea], 10 | 2017,

Publicado el 14 enero 2019, consultado el 19 abril 2019. URL : http://journals.openedition.org/

agedor/1513; DOI : 10.4000/agedor.1513

Este documento fue generado automáticamente el 19 abril 2019.

L'Âge d'or. Images dans le monde ibérique et ibéricoaméricain 


\title{
Configuración de una voz poética piedra a piedra
}

\author{
Paisajes geológicos en Andrés Sánchez Robayna
}

\section{Claire Laguian}

1 La palabra "paisaje" nunca aparece en los poemas de Andrés Sánchez Robayna, a pesar de abarcar su obra más de 45 años desde la publicación en 1970 de su primer poema, hasta los últimos publicados en $2015^{1}$. Pero tampoco es necesario que aparezca este sustantivo puesto que todo es "paisaje" en el poeta canario. Intentaremos abordar la obra robayniana desde los saberes geológicos que construyen y deconstruyen de manera peculiar los cánones de la lectura del paisaje. En efecto, la crítica eligió mayoritariamente estudiar la obra de Sánchez Robayna, y la poesía española contemporánea en general, a partir del prisma de la luz, pero no se ha hablado de la preponderancia de lo mineral, otra materia elemental, en la construcción de los paisajes poemáticos². Sin embargo, la palabra "piedra" aparece 155 veces en la totalidad de la obra poética robayniana, "roca" 70 veces, "arena" 63 veces, y dadas las otras múltiples acepciones de lo geológico en los poemas, desde lo más pequeño hasta lo más imponente (polvo, ceniza, sal, grava, tierra, guijarro, callao, médano, roque, roquedal, malpaís, arrecife, acantilado, barranco, ladera, volcán, isla, etc.), advertimos enseguida la importancia de este ciframiento mineral.

2 Hasta en los títulos de los poemarios domina el elemento más denso, como lo subrayan $L a$ roca (1983), Palmas sobre la losa fría (1988), Sobre una piedra extrema (1995), El libro, tras la duna (2001), y En el centro de un círculo de islas (2007). En singular o en plural, con artículos definidos o indefinidos, la escritura de Sánchez Robayna, como él mismo lo escribe en su primer diario, La inminencia, permite expresar la "variación de la piedra, variaciones emotivas de la piedra" 3 . Lo sensible y lo inteligible de lo mineral crean entonces poemas que permiten buscar la materialidad desaparecida de las palabras.

3 La aridez de la piedra, su peso, su dureza, su inmovilidad, su pasividad, su frialdad y su mutismo inerte no representan, a primera vista, las características más idóneas para poetizar el mundo, al contrario de la luz, el aire, el agua y el fuego simbólicamente activos y muy presentes también en la obra robayniana. No obstante, Sánchez Robayna consigue decir lo inefable al escribir paisajes de piedras temporales, paisajes de piedras 
convergentes, y paisajes de piedras metapoéticas, inspirados por sus distintos viajes y varias experiencias insulares ${ }^{4}$.

\section{Paisajes de múltiples tiempos en la piedra}

4 La piedra sufre la erosión en la naturaleza, y este motivo mineral permite integrar lo indecible de la finitud y de la muerte, que condena al silencio el Cosmos, el ser humano y el lenguaje mismo. El lodo, que se deposita en diferentes capas sedimentarias derivadas de la erosión, sirve en los poemas para expresar la desaparición, tanto como la emoción que le corresponde: "sobre el limo, / sobre la finitud y sobre el llanto"5. En el poema titulado "En la tumba de Stéphane Mallarmé", el verso "Anulación de todo signo"6 se inspira en el propósito estilístico de este poeta francés de ocultar el significado del discurso, y estas palabras representan, en la piedra tumbal misma, el deshacimiento generalizado del sentido. En sus deambulaciones por paisajes cementeriales, la voz poética robayniana enlaza el sentimiento hacia la muerte con el epitafio realmente grabado en las tumbas de piedra, por ejemplo en este homenaje a John Keats: "Las palabras, / en la piedra, fijaban / un breve tiempo de dolor, el nombre / que fue escrito en el agua."

Pero más allá de las palabras incapaces de decir la totalidad de la finitud, la piedra parece en sí más apta que cualquier epitafio para expresar el vacío dejado por la muerte, y para sobrevivir, "persistir", tras la desaparición inexorable: "Había un cementerio / junto al mar. Devastadas, / las piedras persistían / en el aire caliente. / Persistían, calladas, / borradas. ${ }^{8}$ La existencia humana viene ligada a un tiempo insignificante, condenado a la muerte, $\mathrm{y}$ todas las creaciones que usan el mineral en mezclas que le permiten al hombre construir edificaciones, terminan desapareciendo: "respirar entre aquellos muros blancos / la duración, ser con la casa, pura / materia que también / los soles destruirán, pero con ella / fluir, morir". En el poema en prosa titulado "Breve meditación sobre la cal y el tiempo", la mirada del poeta parece alcanzar su máxima precisión cuando es capaz de percibir las huellas de destrucción que deja el tiempo en la materia: "Viste entonces el muro, lo viste de verdad. Sus desconchados eran las heridas del tiempo."10 La fragmentación y multiplicación que se llevan a cabo en los poemas también son una prueba de la obra destruidora del tiempo sobre los objetos humanos fabricados a partir de lo mineral: "Esa tromba de luz sobre la tierra seca / entre restos que copian / el fin de nuestros pasos, / las teselas, las jarras rotas en mil fragmentos sobre el polvo, / obra pura del tiempo, la dispersión del mármol" ${ }^{11}$. Un "amuleto" labrado por un artesano pretende proteger a la voz poética del paso del tiempo, cuando este talismán ni es capaz de retener los propios colores minerales que lo cubrían: "El tiempo borró el polvo de azurita o hematita. Protégeme del ácido del tiempo, ya que no de la tumba, tu oscuridad, tu luz." ${ }^{12}$ Notamos que el motivo de la cal es recurrente en la poesía de Sánchez Robayna, y este material creado por el hombre con la calcinación de mármol, piedras calizas y conchas de animales marinos muertos, parece llevar inexorablemente, a pesar de aplicársele paradójicamente el adjetivo "viva" en la expresión consagrada, a la muerte de la que nadie se salva, ni la pared: "en la violenta luz, cal viva / de irredención sobre el adobe."13 Los paisajes de piedra construidos por el hombre, y condenados a la destrucción por el paso del tiempo, interrogan, por analogía, la permanencia y la eficacia de la labor poética, construcción humana también, para luchar contra la finitud. Estos paisajes geológicos 
permiten la integración, la aceptación quizás por la voz poética, de la existencia de esta muerte, trascendiéndola.

Al mismo tiempo, otra de las tareas que se da el poeta es intentar remontarse a la palabra original, a una palabra ante-predicativa que haya podido existir antes del lenguaje, y hasta antes de la vida. Encontrar los fundamentos lingüísticos se presenta como una suerte de búsqueda de la palabra capaz de decir el milagro de la aparición de la vida. Y, para ello, Sánchez Robayna utiliza un estilo paratáctico, nominal, que nos sitúa directamente en la etapa inicial de la cronogénesis verbal guillaumiana con un uso reiterado y mayoritario de infinitivos, fenómeno característico de la poesía contemporánea y estudiado entre otros por Michel Collot. Si inventáramos una cronogénesis elemental, bien podríamos afirmar que a la etapa del infinitivo le correspondería la piedra, puesto que se da la misma definición de su tiempo en potencia, en palabras de Roger Caillois "[Les pierres] sont d'avant l'homme" ${ }^{14}$, y de la crítica Anne Gourio: "la pierre retient en elle le monde à l'état de virtualité, comme un arrière-fond d'où procède et d'où s'absente l'ensemble des éléments. Elle se révèle donc indissociablement puissance d'actualisation et puissance d'absentement" ${ }^{\prime 15}$.

7 Señal de que la piedra tiene también un poder de vibración y de vida, antes de la vida, Sánchez Robayna cita en un epígrafe unos versos de Virgilio, “...spirantia signa”"16, que describen la respiración de los mármoles de las estatuas, como si estuvieran vivas. El poeta sugiere que los escultores, al moldear las rocas, traspasan su propia vida a la piedra, o tal vez la liberen al sacarla de su latencia: “iLa piedra se atormenta / como la carne? Pudo parecerme / que un estremecimiento la cruzaba, / o era sólo la mano sobre el borde / que contagió a la piedra su temblor." ${ }^{17}$ En las paredes de las profundidades de la tierra, matriz de la vida, los antiguos pintores también dejaron con sus manos el movimiento, la respiración, y hasta un lenguaje no articulado en la piedra:

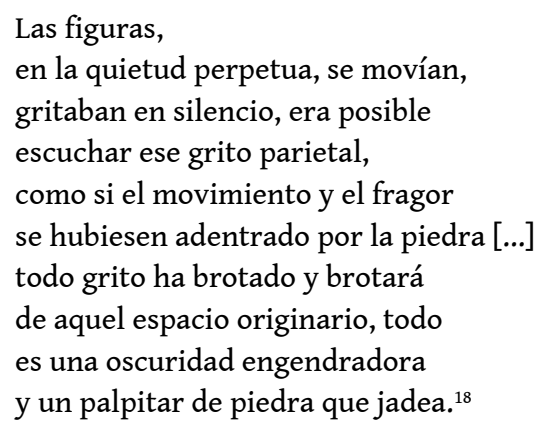

8 Este espacio geológico del origen da a la representación de la piedra el privilegio de poder expresar poéticamente la génesis, con unos cortísimos versos parecidos a piedras que crecen una a una en el camino:

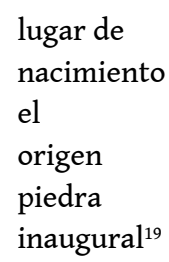

9 Esta génesis deja la vía libre a la posibilidad del alumbramiento de los sentidos ante el enigma ontológico: "La efigie de la piedra, el éxodo / en las arenas alumbradas. Solo / nacimiento a la luz." ${ }^{20}$ Asistimos en el poema "Díptico de la piedra" a un verdadero big bang del Logos poético que combina lecturas minerales, biológicas, físicas y químicas: 


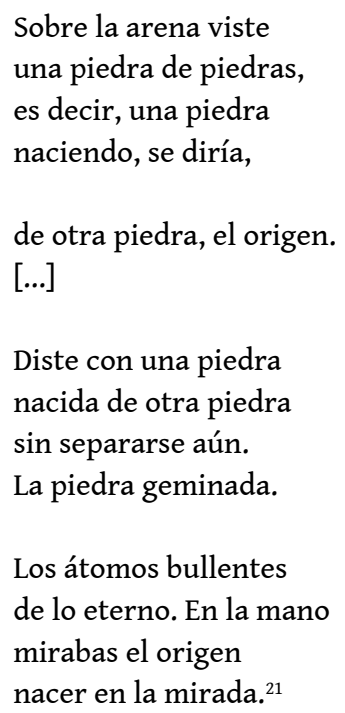

Por consiguiente, la piedra le da al poeta-vidente la clave de comprensión de la aparición de la vida, al reproducirse y al conocer divisiones celulares en un paisaje mineral.

¿Qué característica de la roca permite que el ser humano, en su mínima existencia en la faz de la Tierra, pueda tener acceso a los enigmas temporales que contiene la piedra? El escritor Roger Caillois describe las piedras como unas "archives suprêmes"22, y el motivo del fósil como petrificación de la vida en la roca, "flor de lava / del fósil de la luz" ${ }^{23}$, nos sugiere que la clave de desciframiento del enigma sagrado del origen de los mundos cabe en una piedra: "la memoria / guarda una piedra, cifra del origen." ${ }^{24} \mathrm{El}$ acto de leer también tiene lugar en la piedra, aunque la fugacidad de la existencia de las palabras pueda llevar a su autodesaparición: "Tierra para leer, / leída, pero era como huellas invisibles en dunas / que a sí mismas se borran con el viento nocturno." 25

Si las temporalidades del nacimiento y de la muerte alternan en los paisajes pétreos, también se combinan juntas en una fusión que la piedra cataliza: "Sobre la piedra, un nombre quedó inscrito. / [...] Dio nombre a la criatura y fue epitafio. / Los mundos despertaron en la piedra / comenzante y final." ${ }^{26}$ Los paisajes geológicos y sobre todo el volcanismo, al ser un fenómeno que engendra a la vez muerte y fértil desbordamiento de vida, permiten la unificación de los distintos tiempos: “¿Uno solo el volcán? Eran dos tiempos / unidos, reunidos en los pasos"27. La reunión y la superposición de todos los tiempos verbales en sentencias como ésta: “Una piedra [...] está / y estuvo y estará / siempre allí, / en la orilla desnuda / de la luz perdurable" 28 , nos llevan a la anulación de cualquier temporalidad para intentar alcanzar un tiempo eterno, un tiempo fuera del tiempo. Este tiempo sagrado está en reposo dentro de los paisajes de piedra, como sílabas en suspensión en cada verso que flotan en el espacio de la página:
un
dios
dormita
dentro
de la
roca $^{29}$

13 Pero al mismo tiempo, la abolición de toda temporalidad permite depositar huellas en la escritura poética del éxtasis de la contemplación y del instante, un momento súbito, lapidario, que no se deja fácilmente aprehender por las palabras: "Un breve dios de multiplicada piedra fulgurante" ${ }^{30}$. La escritura poética suele fallar en su búsqueda de la 
palabra eterna, sobre todo cuando la voz lírica se compara con la permanencia de los paisajes de piedra, como en este poema que tiene una forma de apóstrofe, entre envidioso y admirativo, y dirigido "A una roca":

Pero tú quedas. Pero tú, visible

y secreta, te yergues nuevamente

hasta la luz del agua. [...]

mientras tú permaneces, mientras ves

a hombre y ave en su tránsito

cruzar hasta tu linde, tu secreto

incendio bajo el sol, hasta tu negra

forma que yace. $Y$ quedas. $Y$ te yergues

ante todo pasar, bajo los pies del dios. ${ }^{31}$

Entonces, la lucha de la piedra contra el paso del tiempo se cumple a veces exitosamente en los poemas robaynianos, tal como lo señala esta acumulación de verbos de permanencia ("quedas", "te yergues", "permaneces", "yace") que se oponen al "tránsito" humano y animal. La pervivencia eterna de la roca deja ver, por comparación, el carácter insignificante de la temporalidad humana: "Ejes del sol, los roques / medían y medían, / nos medían, ¿y tú, y tú en qué instante / del tiempo estás, te dijeron, y tú / también, no sabes / que eres menos aún / que el ápice brillante / de la ola en el sol?" ${ }^{32}$

El artesano y artista, aunque ya aceptó la finitud de sus obras y de su vida, sigue intentando labrar en la piedra para buscar la forma, la palabra y el sentido que expliquen la totalidad del universo: "Esculpieron con figuras geométricas la piedra destinada a la permanencia" ${ }^{3}$. Es el caso en este poema dedicado al Trono de Ludovisi, escultura de la Antigüedad griega, puesto que interroga el concepto de duración, al conectar las piedras astrales con las piedras terrestres y humanas en un círculo perfecto de reunión de los tiempos sagrados:

Dime, si es que lo sabes: esa piedra, ese trono de mármol indiviso, ¿durará más que el tiempo? [...]

No hay destrucción, dijiste. Volveremos

al seno de la estrella, a la región

del origen y el fin, a la materia

inmortal y materna. Y aunque sólo

quedara de nosotros esa piedra,

esa piedra dirá toda nuestra memoria ${ }^{34}$

Los paisajes de piedra en los poemas de Andrés Sánchez Robayna son, por consiguiente, caminos que la voz poética escoge para intentar aceptar la existencia de la finitud, devolver sus capacidades vitales a lo aparentemente inerte contenido en la cifra mineral, y terminar uniendo las temporalidades en una eternidad y una permanencia geológicas. A veces, la voz poética parece encontrar la palabra sagrada y eterna que diga el milagro metafísico de la existencia, pero ese designio siempre corre el riesgo de fracasar frente a la fragmentación contenida en la piedra y cuya reunificación es por ende imprescindible. 


\section{Convergencias geométricas en la piedra}

17 La roca, por la reversibilidad de sus símbolos y sus múltiples dualidades (de permanencia y de erosión, de archivo memorial y de silencio), es a la vez un agente de simbiosis gracias a la gran variedad de sus estados y a su estatuto transversal entre los demás elementos, como lo señala Bachelard, puesto que la tierra interactúa y se mezcla fácilmente con ellos. De allí, surgen, en los paisajes robaynianos, pasarelas sinestésicas entre los diferentes elementos. Por ejemplo, las nubes aparecen metaforizadas bajo el aspecto de islas en el elemento aéreo: "Islas que el viento zarandea / viajan / en el aire quemado." ${ }^{35}$ Pero uno de los puentes más recurrente entre elementos es el que se crea entre la roca y la luz, como en "la pedrería de la luz" ${ }^{36}$, aunque es necesario precisar a este propósito que las piedras preciosas brillantes son muy escasas en los versos del poeta canario, a pesar de que sea un gran admirador de Mallarmé que usaba mucho este motivo gemológico.

Se trata entonces de varios movimientos de unión y fusión entre luz y piedra, ya que Sánchez Robayna presenta la piedra como nacida de la luz, "La luz creó la roca" ${ }^{37}$, o transustanciada a partir de la luz: "Luz hecha piedra" ${ }^{38}$. Al revés, las piedras son capaces de echar luz en algunos versos, aludiendo así a los astros perdidos en el universo: "luz que se vierte de remotas piedras / y atraviesa la brisa, / llena el espacio, colma / esta dispersa teoría de islas" ${ }^{39}$ Cabe señalar que esta cita, además de integrar una característica a la luz con la característica fluida y líquida del verbo "verterse", permite dar una materialidad espesa a esta luz, transformándola en una suerte de argamasa mineral capaz de llenar el vacío entre cada roca, entre casa isla, tanto como dentro del abismo que existe entre el mundo y las palabras. El elemento aéreo venía atravesado activamente por la luz-piedra en los fragmentos anteriores, pero en la cita siguiente, es el viento el que penetra y se funde en lo geológico: "el viento / buscándose en la tierra en paz, sumida / bajo la piedra, tierra unificada, / arena, sí, de luz o de unidad" 40 . Este panteísmo, muy parecido a lo que la experiencia de la contemplación del paisaje puede producir, unifica a los diferentes reinos como el animal, que representa simbólicamente el aire, y el mineral: "Gaviotas en el claustro viejo: / luz, ala y piedra unidas." ${ }^{11}$ La fusión de las características de lo geológico y del agua permite en la cita siguiente recordar el origen volcánico de la piedra en este poema titulado "A una roca": "negro tranquilo de la forma / las lisas aristas fluyeron / calma fluida lisa negra / soledad entera de la forma" ${ }^{42}$. En efecto, se deduce que la roca negra, acompañada por el sustantivo "arista", es una piedra cortante y áspera, una lava de tipo aa que no tiene entonces ninguna lisura ni fluidez en la realidad extrapoemática. El oxímoron que introduce el elemento líquido nos recuerda por lo tanto el magma original, fuego unitario en el que se encontraban todas las piedras ahora aisladas, tras haber sido expulsadas por la matriz de la tierra, en un claro paralelo con la existencia humana.

La arquitectura sagrada también es motivo de fusión panteísta, siendo el elemento terrestre el que sirve de pasarela entre lo acuático, lo ígneo y lo aéreo: "El que llega a la isla se arriesga a un loco rapto, [...] llevado por las aguas de diamante [...]. Las capillas de cúpulas azules parecieran sembradas a voleo como magma celeste sobre la tierra seca." ${ }^{43}$ Si las islas parecen ser el paisaje más idóneo para llevar a cabo esta reunión elemental, será por la experiencia peculiar que impone un espacio de roca rodeado por el mar, un paisaje insular que el propio Sánchez Robayna describe como catalizador de una "pulsión de espacio" ${ }^{44}$. La isla como lugar de deseo y de fusión: "Sobre la arena negra / se funden y 
confunden / los cuerpos y el ramaje, / bajo la medianoche" ${ }^{45}$. La isla, espacio limitado y cuyo origen geológico se suele vislumbrar más que en el continente, tiene algo de la metonimia del cosmos, del mundo en reducción. En los programas turísticos, se le llama a la isla natal del poeta, Gran Canaria, "continente en miniatura", y esta reunión cosmogónica crea una atracción irresistible entre las temporalidades y los elementos en los versos robaynianos:

entre los bordes de una isla, el fin

de lo que yace en ti, de todo lo que en ti

brota y se extingue,

eres la tierra toda, isla que nos contienes,

isla a la que avanzamos y que vemos venir

a nuestro encuentro

en el centro de un círculo de islas. ${ }^{46}$

Los paisajes de unión pétrea son paisajes de geometría en los versos de Sánchez Robayna, y aquí aparece la voluntad de crear un cosmos ordenado en medio del caos telúrico del mundo. Además de los "triángulos" ${ }^{47}$ de los conos de los volcanes, y del término geométrico y técnico de los versos siguientes, "rumor de / lava / flores / romboides"48, las diferentes líneas paisajísticas y minerales confluyen y se cruzan gracias al motivo final de la piedra en este poema:

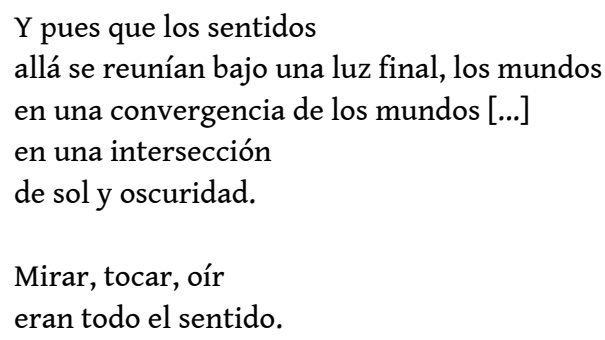

21 Buscar la significación mediante la capacidad constructiva y geométrica de la piedra, también pasa por la simetría y los juegos de inversión que muestran otras perspectivas sobre la realidad. Es el caso en esta "elegía" a Severo Sarduy que recuerda que el ser humano, al mirarse en el espejo de las islas, podrá resolver su pregunta ontológica: "decías / que la isla es el doble / especular del ser en el enigma, / y su exasperación un archipiélago" ${ }^{50}$ La simetría axial, que invierte la orientación del paisaje, se ve reflejada en el fenómeno canario de la calima, cuando la arena del Sáhara flota en el aire, y cuando el sol, al ponerse, parece pasar por debajo de la arena del cielo: "Gira el polvo impalpable / visión de un sol abierto bajo dunas" ${ }^{51}$. En suma, reunir las líneas geométricas de la piedra para volver a la armonía anterior, invertir las visiones para buscar el secreto de la vida.

La piedra tiene otra dimensión espacial que permite una unión peculiar: la vertical. Al enlazar la tierra con el cielo mediante los roques erguidos, no sólo se accede a lo divino, sino que se lucha contra el carácter aplastante y cegador de lo horizontal del mar, del cielo y de la niebla: "junto al mar / que tiembla entre sus rocas finales, // la entera opacidad marina, enhiesta, / las rocas de aquel junio nocturno, // se alzan enteras para reflejarse / [...] y las rocas cubiertas por la niebla / fija, bajo el cielo precipitado." ${ }^{52}$. También se trata de cavar en las profundidades para bucear en el enigma del origen: "Era, tal vez, rasgar, / tocar la entraña de los mundos. / [...] Todo / el rasguño en la piedra" ${ }^{53}$. En su poema vertical, "Elogio", dedicado al escultor Eduardo Chillida, Sánchez Robayna 
describe justamente el oficio del artista-artesano no como una bajada a las explosiones de grisú, sino al alumbramiento de los secretos escondidos en la tierra:

Bajas
minero
en la uniforme luz
ex-
tensa luz mineral
te espera
enciendes
como el minero oscuro
lo mineral
bajas
al alabastro
al astro
blanco
bajas
a la iluminación. ${ }^{54}$

Lo vertical impreso en los paisajes de piedra es entonces una forma de búsqueda órfica del "Conocimiento" 55 , y se da varias veces a través del motivo de la "taparucha", término geológico específico de la isla de La Gomera que designa los diques, especies de muros verticales volcánicos, que quedan tras la erosión. Frente al agua inasible que impide el pensamiento por su volatilidad, la idea y la palabra encuentran un lugar donde resonar en la densidad de la roca más dura que sobrevive a la fragmentación. En estos versos invadidos por los blancos tipográficos, la palabra polisémica "falla" puede, por otra parte, aludir a la fractura dentro de la corteza terrestre: "en la oquedad del olear / las fallas de un pensamiento bajan como / lava de taparuchas / cuando / surge el valle de polvo / la luz reminiscente" ${ }^{56}$. La imposibilidad del ver y del saber, vehiculada por el mar y por el cielo que presentan falsas apariencias de desciframiento, se resuelve entonces en la piedra vertical, bruta y sonante: "pensamiento cerrado en una barca / crispada por soles / y más tarde por la ausencia de sol / en torno / cubre / precipitadamente / salvo en los intersticios de las taparuchas / restallantes" ${ }^{57}$. Esta palabra "intersticio" también aparece en un texto crítico de Andrés Sánchez Robayna y enlaza directamente la posibilidad del saber con el encuentro de la palabra en la intersección de los abismos verticales:

Conocimiento y no-conocimiento, palabra y silencio, interioridad y exterioridad la palabra de la poesía se sitúa tal vez en los intersticios vertiginosos que, en efecto, se abren entre cada uno de esos planos (de esas polaridades), o acaso en sus relaciones o en sus entrecruzamientos..$^{58}$

Como escribía el filósofo místico Maestro Eckhart en el siglo XIV, piedra y palabra contienen en sí la fuerza del conocimiento: « Pierre veut dire connaissance $»^{59}, \mathrm{y}$ :

Les paroles aussi ont grande puissance; on pourrait faire des miracles avec des paroles. Toutes les paroles tirent puissance de la première Parole. Les pierres aussi ont grande puissance de par l'égalité que les étoiles et la puissance du ciel y opèrent. ${ }^{60}$

Pero además de ser motivo de unión y de conocimiento, los paisajes de piedra son también un medio de transformación del poeta mismo al manipular la materia como los antiguos alquimistas, temática a la que volveremos más adelante. Lo mineral en Sánchez 
Robayna es un vector de la búsqueda ontológica, "Te buscaste en las piedras" ${ }^{61}$, tanto como del descubrimiento de la significación de la primera persona, un "yo" muy ausente entre los versos robaynianos: "Contra inmensas laderas sentidos que no sé." ${ }^{62}$ Como lo demostró Merleau-Ponty en sus últimos escritos fenomenológicos, lo visible siempre supone lo invisible, es decir que a los paisajes de piedra que el poeta-vidente puede contemplar, hay que añadirles las profundidades verticales y escondidas de donde salieron las rocas, y que la voz poética debe escuchar tanto como su propio cuerpo, para intentar acceder a la transformación de su ser: "deseas / adentrarte en la luz, / la roca y la presencia, // desnudas, invencibles, / y que sobre la arena / escuchas los latidos / del cuerpo y de la tierra // visibles, invisibles" ${ }^{\prime 63}$.

Los puentes sinestésicos que facilita la piedra entre los elementos son un factor de la escritura panteísta de Andrés Sánchez Robayna que desea buscar el misterio del origen. Las intersecciones geométricas que se trazan en los paisajes geológicos y verticales son otra de las maneras de intentar alcanzar el conocimiento y el sentido global que se niegan a entregarse a la mirada superficial. Pero la búsqueda de una palabra que proporcione un significado alumbrante nunca se resuelve del todo, aunque la voz poética parezca ya haber cerrado un horizonte de pensamiento unitario puesto que, como lo analizó Michel Collot,

Toutefois cette «synthèse des horizons » est toujours présomptive : elle n'aboutit jamais à une unification définitive, puisqu'à mesure qu'elle intègre de nouveaux horizons, elle en suscite encore d'autres qui la débordent. La structure d'horizon est donc à la fois un facteur de synthèse et un principe d'ouverture. ${ }^{64}$

Más que buscar una palabra con la ayuda de los paisajes de piedra, el camino elegido por el poeta español, originario de Canarias, parece orientarse con fuerza hacia una escritura metapoemática de lo mineral, de una palabra que sea mineral.

\section{Metapoesía y partículas elementales en la piedra}

Ya analizamos que la piedra era una suerte de archivo en el que el poeta-vidente podía leer la memoria del origen, pero cabe señalar que la roca también es el lugar en el que se puede grabar, inscribir, como lo recuerda el poemario de Yves Bonnefoy Pierre écrite, y como lo precisa el título de uno de los poemarios de Sánchez Robayna, Inscripciones. La piedra lleva al poeta canario a la escritura, por ejemplo como motivo de intertextualidad al manipular fragmentos de Trilce de César Vallejo ("Y no gritaba, sino que decía / y decía y decía, sólo eso, / piedra prístina y última, infundada ventura, / pura yema infantil / innumerable, madre") o al integrar el título del cuaderno de viaje de Raul Brandão ("Islas desconocidas en el horizonte, casi próximas”). La piedra es un elemento palpable, denso, y árido a la vez, virgen cual una página blanca a pesar de su color negro, y como lo señala Anne Gourio: "La ierre érodée est donc le vecteur, autant que l'expression privilégiée, d'une écriture nue et dépouillée" ${ }^{65}$. Entonces, las laderas del volcán, como las piedras tumbales, acogen las escrituras en el seno de su paisaje caótico: "falda negra y desierta y exacta sobre sí misma inscrita escrita" ${ }^{66}$. La tinta que sirve para escribir en el papel aparece bajo forma de roca negra en este fragmento donde los caparazones de los cangrejos se sustituyen visualmente a las manos del poeta: "recortado en la arena [...] hendido dibujado esculpido contra la roca negra roca mancha de tinta negro sobre negro ante el papel del mar que lee rocas manchas cangrejos que escriben otras líneas" ${ }^{67}$. 
29 Además de la tinta, también aparece otro medio de escritura dentro de lo mineral, a través de la polisemia del término "mina" que puede aludir a la excavación geológica, a la fragmentación de los versos contenidos en el verbo "laminar" puesto de realce por el encabalgamiento, tanto como a la barrita de grafito del lápiz del escritor en medio de la ceniza volcánica: "la tromba de / lapilli la / luz la / mina" ${ }^{68}$. Si se escribe en lo mineral con el mineral, surge la necesidad de existencia de diccionarios que acojan y trasmitan esta lengua pétrea: "diccionario de / sal de / guijarro" ${ }^{69}$. La grabadura de las letras iniciales del poeta, "ASR", en la piedra por parte de un niño, como momento fundador de una poética, aparecen de manera reiterada como la epifanía de la primera página de un poemario en proceso de escritura en la piedra: "Un libro, no visible, iba escribiéndose. / El niño que trazó en la piedra un nombre / y recorrió los médanos solares [...] / Verá formarse el libro, tras la duna." 70

Además de ser la roca un lugar de grabadura, el espacio preciso de la creación poética se autorrepresenta bajo la forma de la piedra, puesto que la roca se transforma en un verdadero poemario. En efecto, la expresión "luz de / mica" ${ }^{71}$ puede aludir a la combinación de las páginas blancas, ya que este mineral se conoce por tener una forma de hojuelas blancas superpuestas. Son muy escasas las referencias a los nombres técnicos y singularizados de los minerales en Sánchez Robayna, como ya lo señalamos, pero cuando aparecen, suelen integrarse en una labor metapoética de lo geológico, como en esta cita que alude al margen de la página: "cae una luz al borde cadmio del poema" 72 . Si nos fijamos en el fragmento siguiente, "el mar margen vuelto y escrito por el solhendido en la página pétrea que reposa donde el habla medita en el cuaderno deshojado en la arena"73, podemos destacar el proceso de escritura latente que deja correr el pensamiento mineral, antes de poetizarlo en la página de piedra cuyo margen corresponde al elemento líquido. Se reconoce aquí el contenido de uno de los aforismos de Sánchez Robayna en su Cuaderno de las islas, "Un poema es una isla de lenguaje en el mar del silencio" ${ }^{4}$, aforismo en el que hay una coincidencia total, indicada por el verbo copulativo "ser", entre el elemento geológico insular y el poema. Este aforismo también puede ser un eco de Roger Caillois cuando afirmaba: "Plus d'une fois, cependant, il m'est arrivé de penser qu'il convenait aussi de regarder les pierres comme des sortes de poèmes" ${ }^{75}$. Dado que el poema es piedra en Sánchez Robayna, adopta tipográficamente las múltiples apariencias que le corresponden al paisaje mineral, tal como lo expresa programáticamente el título de este texto: "El poema tendrá la forma de un grupo de rocas" ${ }^{76}$. El poema también puede presentarse bajo la forma de un verdadero bloque mineral, un acantilado de palabras, que se da visualmente al lector gracias al poema en prosa siguiente:

Unidad

Gime la masa de los árboles. En el barranco, sacos, un círculo de piedras, el sol de las seis, la perfecta inmovilidad, el pinar en la línea curva de las últimas montañas, los ojos amarillos del gato negro. En los ojos del gato el sol sestea. La masa de los árboles, el agua estancada, ramas secas, el camino de piedras, bolsas de plástico brillante y negro movidas por el viento, arbustos displicentes, obedientes, milanos errabundos, los pájaros negros en el círculo henchido de las ramas de una palmera, eco de aguas que fluyen. En mis oídos suena el agua ronca del aire entre los platanares. El sol en una roca, la roca soleada, los actos del viento, las sombras de las piedras. Desde la ventana, todo respira y se responde: el vuelo circular de una golondrina, la tunera reseca, el cardón erecto, la sombra fugitiva de la golondrina, el arco de la pata del gato en la roca soleada - el salto sigiloso, misterioso, las ramas secas, el murmullo cada vez más denso, las palabras que acalla el soplo ardiente, el golpear del viento de las seis de la tarde al fondo del barranco. ${ }^{77}$ 
vierto sílabas

líneas

hiatos

(rueda la ola

solar)

solas

olas

contra el acantilado blanco ${ }^{79}$

Este "acantilado blanco", semejante a la página macroscópica "contra" la que se van a disponer las palabras del poeta-vidente, también trae consigo una dimensión microscópica, lo que podríamos denominar una piedra como partícula elemental que aparecía en esta cita anterior con los términos metapoéticos "líneas", "hiatos", "sílabas". En efecto, la piedra, además de ser poema, también es palabra, sonido, y hasta sílaba. Pensar el mundo poético como el mundo geológico le permite al poeta evitar separar de manera demasiado tajante las cosas y la palabra. La materialidad de la piedra ya no sólo es un motivo para escribir, sino la herramienta misma que trasmite la significación más allá del silencio: "Mudo caminas bajo el día de aire. / Excavas en la orilla la palabra / que dice el mar soplado." ${ }^{\circ 0} \mathrm{El}$ epígrafe, sacado de los versos del poeta vanguardista brasileño Haroldo de Campos "Sintaxe e / dunas", introduce la escritura de una piedra que tiene el mismo poder de ciframiento que los signos lingüísticos: "Dos o tres rocas / en el mar de las islas. / Son los signos, / los médanos." ${ }^{81} \mathrm{El}$ carácter denso de los paisajes minerales parece ser en Sánchez Robayna una solución verbal frente al abismo que se cava permanentemente en el discurso humano entre la sensación y la palabra: "En la piedra que ocupa / el lugar de la boca." ${ }^{2}$, "Plenitud de la piedra que parece colmar el espacio vacío.» ${ }^{83} \mathrm{El}$ poeta canario se adentra aún más profundamente en la materia al penetrar en la palabra cuando reúne con lo mineral un elemento métrico y rítmico de la antigüedad latina compuesto de dos sílabas largas, el espondeo: "latidos rocosos espondeos." ${ }_{84}$

Ritmo y musicalidad poética se funden con la roca, y esto enlaza con el mito de Orfeo que como poeta tenía el poder de dar a las piedras el don de producir música con su lira. Es 
uno de los designios que aparecen en el primer diario de Sánchez Robayna, La inminencia, donde precisa su meta poética: "Percusión de la roca: poema litofónico. El sonido del enigma de ser." ${ }^{85} \mathrm{El}$ poema dedicado a un "Madrigal" barroco de Monteverdi, lleva a cabo la transformación de la piedra en voz cantante y en nota de música dentro del paisaje mineral:

sólo filos tejidos de luz roca viva en el fondo de voces fijas como rocas [...] ego dormio sobre la luz en la lava cordada de la costa voces también cordadas [...] et cor meum y así et cor meum montañas recorridas por las voces cordadas. ${ }^{86}$

La polifonía y la fluidez de lo sonoro se desarrollan en el poema con la expresión "voces cordadas" que puede aludir a la "lava cordada", término canario que designa la forma retorcida y trenzada que adoptan las coladas de lava fluida al enfriarse, como cuerdas superpuestas de un mismo instrumento. Entonces, la piedra es poema, palabra y nota de música, pero además Sánchez Robayna compara el oficio del poeta con el de un "picapedrero" que va buscando en el borde del lenguaje un elemento aún más pequeño, y fundamental en la dimensión sonora y rítmica de la poesía, la sílaba: "Picapedrero ignoto esculpo nada / de sol / como él golpeo un desierto / detrás / de la sílaba negra un puro precipicio / colmado de su estancia" ${ }^{87}$.

La manipulación de la piedra-sílaba en el tránsito poético de Andrés Sánchez Robayna se asemeja al saber alquimista que pretendía convertir la piedra en oro para alcanzar la eternidad y la transformación del ser gracias a la transmutación de los metales: "mediodía de / siglos / sílabas / auríferas / ya / caminé antes / aquí / en el oro / en el aura." ${ }^{88}$ Se lleva a cabo una transustanciación de lo mineral en verbal, y viceversa. Esto pasa por el proceso alquímico que encierra la sonoridad poética con la transmutación sonora de las palabras desde el latín, de aurum a "oro", y con el juego de encabalgamiento en mitad del adjetivo "son-/oro":

Llegó un día una multi-

facetada palabra: en cada faz

una sílaba aurífera

como suspensa en un

ofuscador celaje de oroluz,

pedrería estelar,

ajedrez diamantino

de palabras pensantes

cayendo vivas en

la celdilla del ojo

pineal, un galáctico

ritmo de astros verbales

con un son-

oro sol interior que alumbra el mundo. ${ }^{89}$

La piedra-sílaba es entonces la herramienta sintáctica más elemental necesaria a la construcción de los versos poéticos, y el fragmento, "Como la roca matinal en átomos / de albor, de luz despedazada, / bebe, cuerpo, el rocío de los mundos" ${ }^{90}$, confirma la concepción elemental, e incluso química, de la escritura robayniana, heredada del pensamiento de los presocráticos, para quienes la letra era un átomo.

Para concluir, diremos que la búsqueda de una palabra poética capaz de colmar el espacio ontológico entre el mundo y el discurso, y de trascender la muerte, pasa en Sánchez Robayna por la poetización de los paisajes de piedra. Se lleva a cabo mediante una petrificación de las distintas temporalidades, hasta su fusión que se opera también entre los elementos naturales que componen el paisaje gracias a las pasarelas sinestésicas. Las 
convergencias geométricas de lo mineral intentan ordenar el caos en que se sumerge la vida, para alcanzar una forma de conocimiento proveniente de la piedra. La escritura metapoética de la roca convierte el espacio del poema en verdaderos paisajes geológicos que dan una faceta sonora y eterna a la palabra poética. En realidad, la lucha contra lo indecible en los poemas robaynianos adopta el lenguaje mineral capaz de crear un cosmos:

$$
\text { [...] ¿Qué llevó, }
$$

sin embargo, la mano hasta una piedra

lisa casi y sin luz y, con otra, pequeña,

a escribir en lo claro

de sus bordes un nombre, una inscripción

sobre la piedra, nunca arrebatable

por la muerte? ¿Una forma

de ser tan solo cosa de la luz?

Una palabra mineral.

Bajo el último sol, me pareció decir

una palabra, acaso, contra lo impermanente.

¿Comenzaba allí un libro? ${ }^{91}$

\section{NOTAS}

1. Unos poemas inéditos incluidos en Al cúmulo de octubre (Antología poética: 1970-2015) y que pertenecen a un poemario en preparación.

2. Cabe señalar que, un año después de la escritura de este artículo, coordiné la publicación del monográfico en torno a la obra de Andrés Sánchez Robayna en el número 29 de Tropelías: Revista de Teoría de la Literatura y Literatura Comparada de la Universidad de Zaragoza. Se publicó en febrero de 2018 en https://papiro.unizar.es/ojs/index.php/tropelias/issue/view/191, y contiene un ensayo de Alejandro Rodríguez-Refojo titulado "Tres símbolos y una metáfora en la poesía de Andrés Sánchez Robayna” que dedica un capítulo a las variaciones simbólicas de la piedra (p. 102-105). El ensayo de Claudie Terrasson, “Andrés Sánchez Robayna: El libro, tras la duna. Diálogos con José Ángel Valente e Yves Bonnefoy”, también alude a esta temática (p. 161-167).

3. Andrés, Sánchez Robayna, La inminencia: diarios (1980-1995), Madrid, Fondo de Cultura Económica, 1996, p. 91.

4. Canarias, por supuesto, pero también las islas griegas o Cuba.

5. Andrés, Sánchez Robayna, En el cuerpo del mundo, Barcelona, Galaxia Gutenberg, 2004, p. 354.

6. Andrés, Sánchez Robayna, La sombra y la apariencia, Barcelona, Tusquets, 2010, p. 213.

7. Ibid., p. 61.

8. Ibid., p. 95.

9. Ibid., p. 81.

10. Ibid., p. 231.

11. Ibid., p. 132.

12. Ibid., p. 145.

13. Andrés, Sánchez Robayna, En el cuerpo del mundo, op. cit., p. 203. 
14. Roger, Caillois, Pierres, in La lecture des pierres, Paris, Éditions Xavier Barral, 2014, p. 7. Cabe destacar que la perspectiva de estudio de las piedras por parte de Roger Caillois no es exactamente la misma que la que elegimos, puesto que este autor francés privilegia la escritura de las gemas y de las piedras figuradas.

15. Anne, Gourio, Chants de pierres, Grenoble, ELLUG, 2005, p. 366.

16. Andrés, Sánchez Robayna, En el cuerpo del mundo, op. cit., p. 202.

17. Ibid., p. 332.

18. Ibid., p. 411-412.

19. Ibid., p. 190.

20. Ibid., p. 12.

21. Andrés, Sánchez Robayna, La sombra y la apariencia, op. cit., p. 143-144.

22. Roger, Caillois, Le fleuve Alphée, Paris, Gallimard, 1978, p. 86.

23. Andrés, Sánchez Robayna, En el cuerpo del mundo, op. cit., p. 141.

24. Ibid., p. 328.

25. Ibid., p. 264.

26. Ibid., p. 334.

27. Ibid., p. 316.

28. Andrés, Sánchez Robayna, La sombra y la apariencia, op. cit., p. 143.

29. Andrés, Sánchez Robayna, En el cuerpo del mundo, op. cit., p. 143.

30. Ibid., p. 283.

31. Ibid., p. 209-210.

32. Andrés, Sánchez Robayna, La sombra y la apariencia, op. cit., p. 97.

33. Andrés, Sánchez Robayna, En el cuerpo del mundo, op. cit., p. 282.

34. Andrés, Sánchez Robayna, La sombra y la apariencia, op. cit., p. 67-68.

35. Andrés, Sánchez Robayna, En el cuerpo del mundo, op. cit., p. 39.

36. Ibid., p. 370.

37. Ibid., p. 25.

38. Andrés, Sánchez Robayna, La sombra y la apariencia, op. cit., p. 105.

39. Ibid., p. 75.

40. Andrés, Sánchez Robayna, En el cuerpo del mundo, op. cit., p. 203.

41. Andrés, Sánchez Robayna, La sombra y la apariencia, op. cit., p. 55.

42. Andrés, Sánchez Robayna, En el cuerpo del mundo, op. cit., p. 145.

43. Andrés, Sánchez Robayna, La sombra y la apariencia, op. cit., p. 225.

44. Andrés, Sánchez Robayna, "Epílogo”, in En el cuerpo del mundo, op. cit., p. 433.

45. Andrés, Sánchez Robayna, En el cuerpo del mundo, op. cit., p. 21.

46. Andrés, Sánchez Robayna, La sombra y la apariencia, op. cit., p. 135.

47. Andrés, Sánchez Robayna, En el cuerpo del mundo, op. cit., p. 164.

48. Ibid., p. 149.

49. Ibid., p. 331.

50. Ibid., p. 312.

51. Ibid., p. 73.

52. Ibid., p. 34-35.

53. Ibid., p. 330.

54. Ibid., p. 193.

55. Ibid., p. 33

56. Ibid., p. 79-80.

57. Ibid., p. 74.

58. Andrés, Sánchez Robayna, “Epílogo”, in En el cuerpo del mundo, op. cit., p. 431.

59. Maître Eckhart, L'étincelle de l'âme. Sermons I à XXX traduits et présentés par Gwendoline Jarczyk et Pierre-Jean Labarrière, Paris, Albin Michel, 1998, p.51. En la nota de este sermón 3, aparece la 
precisión siguiente: « Les clefs, signe distinctif de l'apôtre Pierre, symbolisent le pouvoir d'ouvrir ce qui était fermé ».

60. Ibid., sermón 18, p. 180.

61. Andrés, Sánchez Robayna, En el cuerpo del mundo, op. cit., p. 13.

62. Ibid., p. 33.

63. Andrés, Sánchez Robayna, La sombra y la apariencia, op. cit., p. 19.

64. Michel, Collot, La poésie moderne et la structure d'horizon, Paris, Presses Universitaires de France, 1989, p. 24.

65. Anne, Gourio, op. cit., p. 225.

66. Andrés, Sánchez Robayna, En el cuerpo del mundo, op. cit., p. 111.

67. Ibid., p. 122.

68. Ibid., p. 164.

69. Ibid., p. 172.

70. Ibid., p. 392.

71. Ibid., p. 176.

72. Ibid., p. 55.

73. Ibid., p. 121.

74. Andrés, Sánchez Robayna, Cuaderno de las islas, Barcelona, Lumen, 2011, p. 50.

75. Roger, Caillois, Le champ des signes : récurrences dérobées, aperçu sur l'unité et la continuité du monde physique intellectuel et imaginaire ou premiers éléments d'une poétique généralisée, Paris, Hermann, 2008, p. 7.

76. Andrés, Sánchez Robayna, En el cuerpo del mundo, op. cit., p. 51.

77. Ibid., p. 97.

78. Ibid., p. 81.

79. Ibid., p. 83.

80. Ibid., p. 12.

81. Ibid., p. 24.

82. Ibid., p. 333.

83. Andrés, Sánchez Robayna, La sombra y la apariencia, op. cit., p. 33.

84. Andrés, Sánchez Robayna, En el cuerpo del mundo, op. cit., p. 80.

85. Andrés, Sánchez Robayna, La inminencia: diarios (1980-1995), op. cit., p. 59.

86. Andrés, Sánchez Robayna, En el cuerpo del mundo, op. cit., p.117.

87. Ibid., p. 76.

88. Ibid., p. 189.

89. Ibid., p. 407.

90. Ibid., p. 294.

91. Ibid., p. 329-330.

\section{RESÚMENES}

En este texto, estudiamos la poetización de los paisajes de piedras en los poemarios de Andrés Sánchez Robayna, poeta español contemporáneo, originario de las islas Canarias. Símbolo reversible que permite trascender la muerte, el mineral también busca la epifanía del sentido al establecer convergencias temporales y geométricas que desembocan en una escritura 
metapoética del motivo rocoso, capaz de decir lo indecible mediante un ahondamiento en lo elemental.

Dans ce texte, nous étudions la poétisation des paysages de pierres dans les recueils d'Andrés Sánchez Robayna, poète espagnol contemporain, originaire des îles Canaries. Symbole réversible permettant de transcender la mort, le minéral recherche également l'épiphanie du sens en établissant des convergences temporelles et géométriques qui débouchent sur une écriture métapoétique du motif rocheux, capable de dire l'indicible par une plongée dans l'élémentaire.

ÍNDICE

Palabras claves: Sánchez Robayna (Andrés), mineral, metapoesía, alquimia, geometría Mots-clés: Sánchez Robayna (Andrés), minéral, métapoésie, alchimie, géométrie

\section{AUTOR}

\section{CLAIRE LAGUIAN}

Université Paris-Est Marne-la-Vallée (LISAA, EA4120) 